\title{
The analysis of psychological aspects of online education: Depression and happiness and their relationship with college students' academic achievement
}

\author{
Atefeh Avaznia \\ Kerman University of Medical Sciences \\ Hamid Reza Shoraka \\ Kerman University of Medical Sciences \\ Esmat Nouhi ( $\nabla_{\text {e_nuhi@kmu.ac.ir) }}$ \\ Kerman University of Medical Sciences
}

\section{Research Article}

Keywords: Internet addiction, social media, students, academic achievement, happiness, depression

Posted Date: March 1st, 2021

DOI: https://doi.org/10.21203/rs.3.rs-254624/v1

License: (c) (i) This work is licensed under a Creative Commons Attribution 4.0 International License.

Read Full License 


\title{
The analysis of psychological aspects of online education: Depression and happiness and their relationship with college students' academic achievement
}

\author{
Atefeh Avaznia ${ }^{1}$, Hamid Reza Shoraka ${ }^{2}$, Esmat Nouhi ${ }^{3}$ *
}

1- Master student Medical Education, Educational Management Research Center, Kerman

University of Medical Sciences

2- PhD student in Statistics and Epidemiology, Faculty of Health, University of Medical

Sciences

3- Correspondence: Esmat Nouhi, Department of Medical Surgical Nursing, School of Nursing and Midwifery, Kerman University of Medical Sciences, Kerman, Iran.

ID: 0000-0003-1906-4146

e_nuhi@kmu.ac.ir

\begin{abstract}
Background: Physical and psychological problems faced by college students during the COVID-19 pandemic and via online education can be investigated and prevented. Internet addiction, especially in online education, affects the student's academic and social life. This study aimed to explore the psychological aspects of depression and happiness due to Internet addiction and their relationships with students' academic achievement.

Methods: This cross-sectional study was conducted on 510 students who were studying at Kerman University of Medical Sciences in 2019. The students were selected using multistage cluster sampling. The instruments used to collect the data were three standard
\end{abstract}


questionnaires and a data collection form. The collected were analyzed statistically with SPSS software (version 22).

Results: The mean score of Internet addiction was $36.73 \pm 18$. Overall, 140 students (27.4\%) were at the pre-addiction stage and 19 students (3.7\%) were severely dependent on the Internet and social media. Internet addiction had a significant correlation with depression and happiness. However, no significant relationship was observed between Internet addiction and academic achievement. The results of multivariate linear regression analysis showed that Internet addiction was significantly correlated with the students' age ( $P=0.047)$, marital status $(P=0.001)$, and academic level $(P=0.002)$.

Conclusion: The results of this study suggested approximately one-third of students were dependent on the Internet and social media or were about to become addicted. The results also confirmed the link between Internet addiction with depression and happiness in the students. Thus, Internet addiction showed a negative correlation with happiness but a positive correlation with addiction and depression. However, no significant relationship was observed between Internet addiction and academic achievement. Although the use of online education is a complementary and effective educational technique, it should be carefully managed in educational programs.

Keywords: Internet addiction, social media, students, academic achievement, happiness, depression

\section{Background}


Internet access is growing fast, with a greater number of people becoming Internet users each day. The Internet is everywhere: at home, at school, and even in malls, and the number of Internet users is growing dramatically [1] In Iran, the use of the Internet has been increasing rapidly since the beginning of the century. Besides, the use of social media and networks has become widespread in the last decade and, according to the Statistical Center of Iran, more than 47 million Iranians use social media and networks [2].

Along with the growing access of people to the Internet, we are witnessing a new type of addiction, i.e. Internet addiction, which is a growing issue in the Information Age [3]. Ivan Goldberg first introduced Internet addiction in 1995, which develops a kind of behavioral dependence on the Internet in people and acute cases can manifest themselves as a disease that needs treatment. Many patients are unaware of it or do not take it seriously. In his article, Goldberg states that the first step in treating Internet addiction is to be aware of one's illness [4-6].

Like all other forms of addiction, Internet addiction is associated with symptoms such as anxiety, depression, mood swings, restlessness, obsessive thoughts, isolation, emotional disorders, and social breakdown. There are various statistics on the prevalence of Internet addiction in different societies. But on average, the proportion of addicts is about 2 to 5 million for every 50 million regular users. In other words, it can be suggested that approximately 5 to $10 \%$ of Internet users have addiction problems [3].

Various studies conducted on students have suggested that the use of the Internet, as well as the incidence and prevalence of Internet addiction, is increasing and is associated with problems such as reduced interpersonal communication, anger, aggression, and excitement. 
Internet addiction also increases academic failure in this group [4].Young's studies suggested that $50 \%$ of students who regularly use the Internet had lower grades and paid less attention to instructions provided in the classroom [7-9].

Donnelly et al. (2016) found a positive relationship between Instagram addiction and depression [10]. Rastgar et al. (2014) explored Internet addiction, social intimacy, and happiness in college students using the Oxford Happiness Inventory. The results showed no significant difference between the two groups of healthy users and users with mild Internet addiction in terms of happiness and social intimacy. However, the level of happiness and social intimacy reported by both groups was significantly higher compared to the group of users with acute Internet addiction [11].

Given the importance and widespread use of the Internet and social media in higher education and their effects on the social and academic life of students, this study explores the association of Internet addiction with students' academic achievement, depression, and happiness.

\section{Methods}

\section{Design}

This cross-sectional study was conducted on students of Kerman University of Medical Sciences.

\section{Sample and eligibility}

The participants were selected using multi-stage cluster sampling. To this end, each faculty was considered as a cluster. First, 5 faculties were randomly selected from among the faculties of the university, and the sample size for each faculty was calculated in 
proportion to the number of students in each faculty. In the next stage, several classes were randomly selected from each faculty and the questionnaires were completed for all students of the selected classes.

The inclusion criterion for attending the study covered all students studying at Kerman University of Medical Sciences. Students who were not willing to participate in the study for any reason, people who were replaced by accident, and also freshman students were not included in the study because they are newcomers and no grade point average was calculated for them.

Various studies were reviewed to calculate the sample size. The prevalence of Internet addiction among students of Kurdistan University of Medical Sciences was reported by Vahabi et al. (2015) to be $30 \%$ [12].Using the sample size calculation formula for two independent groups and considering the prevalence of $30 \%$, the sample size was estimated as 510 persons.

The instruments used to collect the data were three standard questionnaires and a data collection form. The data collection form assessed the participants' age, marital status, academic level, place of residence, college, and field of study.

\section{Questionnaire design}

\section{Internet and Social Network Addiction Questionnaire}

To measure Internet addiction, a self-administered social media addiction questionnaire developed by Khajeahmadi et al. (2015) was used [13]. This questionnaire was the localized and updated version of Young's Addictive Use of the Internet Questionnaire[14].The questionnaire contained 23 items that were scored on a five-point 
Likert scale ranging from Disagree, Somewhat Disagree, No Comment, Somewhat Agree, and Agree. The scores ranged from 0 to 92, with a higher score indicating greater Internet addiction and more severe problems resulting from overuse of the person. To interpret the score obtained from administering the questionnaire, the instructions provided by the developer were used. Accordingly, a score of 0 to 23 indicated a lower-than-normal user, a score of 24 to 46 indicated a normal user, a score of 47 to 70 indicated a pre-addicted user, and a score of 71 to 92 denoted an addicted user.

\section{Oxford Happiness Inventory}

The Oxford Happiness Inventory (OHI) was used to measure the students' happiness [15]. The validity and reliability of the Persian version of the inventory were assessed by Alipoor and Noorbala (1999) by administering it to students of Tehran University [16].The inventory contains 29 items, each with four statements scored from 0 to 3, respectively. The total score ranges from 0 to 87 , with a higher score indicating a greater level of happiness.

\section{Patient Health Questionnaire (PHQ-9)}

The Patient Health Questionnaire (PHQ-9) was used to assess the students' depression. This questionnaire contains 9 items that assess the individual's condition in the last two weeks. The items are scored based on a four-point Likert scale from never to almost every day and were developed by Kroenke et al. (2001) with 88\% sensitivity and specificity for diagnosing depression. A score of 1 to 4 shows no depression, a score of 5 to 9 denotes mild depression, a score of 10 to 14 indicates moderate depression, a score of 15 to 19 
shows relatively severe depression, and a score of 20 to 27 indicates severe depression [17].Before completing the questionnaires, one of the researchers provided the students with some explanations about the objectives of the study and how to complete the questionnaires. The students were free no to complete the questionnaire if they wished so. The average time given to the students to complete the questionnaires was 25 minutes.

\section{Data analysis}

The collected data were coded and analyzed using SPSS software (version 22) through linear regression analysis and Pearson correlation test at the significance level of $0.05(\mathrm{P}=$ $0.05)$.

\section{Ethical approval}

The ethical principles for medical research involving human subjects under the Declaration of Helsinki (2013) were observed in all stages of the study. Also, the research proposal was reviewed by the Ethics Committee of Kerman University of Medical Sciences and was registered with the code IR.KMU.REC.1397.515. All methods were carried out in accordance with relevant guidelines and regulations in the Ethical Declarations.

\section{Results}

A total of 545 students of Kerman University of Medical Sciences were selected from 5 faculties of health, paramedical sciences, management, and information, pharmacy, and nursing and midwifery to participate in the study. Fourteen students refused to participate in the study and 21 students who did not answer all items in the questionnaire were 
excluded from the study and finally, the data from 510 questionnaires completed by the students were used in the data analysis.

The results showed $71.6 \%$ of the students participating in this study were female, $84.9 \%$ of them were single and $78.5 \%$ of the participants were undergraduate students. Furthermore, $54.7 \%$ of the students lived in dormitories and $86.8 \%$ of the students were in the age group of $18-25$ years. The average age of the students was $22.09 \pm 4.27$ years, ranging from 17 to 44 years, and $40.8 \%$ of students spent over 3 hours per day on social media (Table 1).

It was also shown that 140 students $(27.4 \%)$ were at risk of internet addiction and 19 (3.7\%) are addicted to the Internet and social networks (Table 2). Besides, of the social media commonly used in the country, $7.95 \%$ of students used Telegram, $75.9 \%$ used Instagram, and 55.9\% used WhatsApp messenger and only $4.7 \%$ of students used Iranian social networks (Table 3).

Table 1: The descriptive statistics for the participants' demographic data

\begin{tabular}{|l|l|l|l|}
\hline Variable & Nale & Number & Percentage \\
\hline \multirow{4}{*}{ Gender } & Female & 145 & 28.4 \\
\cline { 2 - 4 } & $18-25$ & 365 & 71.6 \\
\cline { 2 - 4 } & $26-35$ & 443 & 86.9 \\
\cline { 2 - 4 } & $36-45$ & 56 & 11 \\
\hline Marital status & Single & 11 & 2.2 \\
\cline { 2 - 4 } & Married & 433 & 84.9 \\
\cline { 2 - 4 } & Divorced/widow & 6 & 13.9 \\
\hline Faculty & Paramedic & 122 & 1.2 \\
\cline { 2 - 4 } & Sciences & & 23.9 \\
\cline { 2 - 4 } & Management & 65 & 12.7 \\
\cline { 2 - 4 } & Health & 136 & 26.7 \\
\cline { 2 - 4 } & Nursing & 143 & 28 \\
\cline { 2 - 4 } & Pharmacy & 44 & 8.6 \\
\hline Accommodation & Local & 193 & 37.8 \\
\cline { 2 - 4 } & Dormitory & 279 & 4.3 \\
\cline { 2 - 4 } & Private house & 22 & \\
\hline
\end{tabular}




\begin{tabular}{|l|l|l|l|}
\hline \multirow{5}{*}{ Academic level } & Other & 16 & 3.2 \\
\cline { 2 - 4 } & $\begin{array}{l}\text { Bachelor's } \\
\text { degree }\end{array}$ & 400 & 78.4 \\
\cline { 2 - 4 } & Master's degree & 35 & 6.9 \\
\cline { 2 - 4 } & Ph.D. & 29 & 5.7 \\
\cline { 2 - 4 } & Ph.D. & 46 & 9 \\
\hline Social media use (hours) & Non-user & 1 & 0.2 \\
\cline { 2 - 4 } & $>05$ & 22 & 4.3 \\
\cline { 2 - 4 } & $0.5-1$ & 50 & 9.8 \\
\cline { 2 - 4 } & $1-2$ & 90 & 17.6 \\
\cline { 2 - 4 } & $2-3$ & 139 & 27.3 \\
\cline { 2 - 4 } & $<3$ & 208 & 40.8 \\
\hline
\end{tabular}


Table 2: The severity of the internet addiction among the participants

\begin{tabular}{|l|l|l|l|l|l|l|l|l|l|}
\hline \multicolumn{2}{|l|}{ Overall severity of the Internet addiction } & \multicolumn{2}{l|}{ Total } \\
\hline Less than normal & \multicolumn{2}{l|}{ Normal } & Pre-addiction & Addicted & \multicolumn{2}{l|}{} \\
\hline Number & $\begin{array}{l}\text { Perce } \\
\text { ntage }\end{array}$ & $\begin{array}{l}\text { Num } \\
\text { ber }\end{array}$ & $\begin{array}{l}\text { Perce } \\
\text { ntage }\end{array}$ & $\begin{array}{l}\text { Num } \\
\text { ber }\end{array}$ & $\begin{array}{l}\text { Perce } \\
\text { ntage }\end{array}$ & $\begin{array}{l}\text { Num } \\
\text { ber }\end{array}$ & $\begin{array}{l}\text { Perce } \\
\text { ntage }\end{array}$ & $\begin{array}{l}\text { Num } \\
\text { ber }\end{array}$ & $\begin{array}{l}\text { Percen } \\
\text { tage }\end{array}$ \\
\hline 126 & 24.7 & 225 & 44.2 & 140 & 27.4 & 19 & 3.7 & 510 & 100 \\
\hline
\end{tabular}


Table 3: The use of common social media across the country

\begin{tabular}{lll}
\hline Social media & Number & Percentage \\
\hline Telegram & 488 & 95.7 \\
Instagram & 387 & 75.9 \\
WhatsApp & 285 & 55.9 \\
YouTube & 90 & 17.6 \\
Facebook & 34 & 6.7 \\
Iranian media & 24 & 4.7 \\
Skype & 4 & 0.8 \\
None & 2 & 0.4 \\
\hline
\end{tabular}

The linear correlation between the three instruments used in this study including the Internet and Social Network Addiction Questionnaire, the Oxford Happiness Inventory, and the Patient Health Questionnaire (PHQ-9) was assessed. The results showed a significant correlation between the three instruments used in the study. Thus, there was a negative correlation between Internet addiction and happiness. Accordingly, as the value of one of these variables increased, the other variable decreased. For example, an increase in the Internet addiction would lead a decrease in happiness $(r=-0.34),(P<0.0001)$. There was a positive correlation between Internet addiction and depression and thus an increase in one of these variables would lead to a decrease in the other variable $(\mathrm{r}=0.36),(\mathrm{P}$ $<0.0001)$. Finally, there was a negative correlation $(r=-0.51)$ between depression and happiness indicating that as the student's depression increases they reported a lower level of happiness and vice versa $(\mathrm{P}<0.0001)$ (Table 4).

First, all variables were evaluated using univariate analysis, and the variables with significant values were added into a multivariate model. The backward method was used in 
multivariate analysis and all variables with a P-value less than 0.05 were kept in the model. The results of multivariate linear regression analysis showed that there was a significant relationship between Internet addiction with age $(\mathrm{p}=0.047)$, marital status $(\mathrm{p}=0.001)$, and academic level $(\mathrm{p}=0.002)$. Although there was a significant relationship between the students' gender the Internet addiction in univariate analysis, they were not significantly correlated in multivariate analysis (Table 5). The result of the Spearman correlation test also showed no significant correlation between Internet addiction and academic achievement (Table 4).

Table 4: Correlations between the internet addiction, happiness, and depression

\begin{tabular}{lllll}
\hline Variable & \multicolumn{2}{l}{ Internet addiction } & \multicolumn{2}{l}{ Happiness } \\
& $\mathrm{r}$ & P-value & $\mathrm{r}$ & P-value \\
\hline Internet & - & - & - & - \\
addiction & & & & \\
Happiness & -0.34 & $0.0001>$ & - & - \\
Depression & 0.36 & $0.0001>$ & -0.51 & $0.0001>$ \\
Academic & & & & - \\
achievement & -0.028 & 0.52 & - & \\
\hline
\end{tabular}


Table 5: The results of univariate and multivariate regression analysis for the effect of the research variables on the internet addiction

\begin{tabular}{|c|c|c|c|c|c|c|}
\hline \multirow[b]{2}{*}{ Variable } & \multirow[b]{2}{*}{ Category } & \multirow[b]{2}{*}{ Mean } & \multicolumn{2}{|l|}{ Univariate } & \multicolumn{2}{|c|}{ Multivariate } \\
\hline & & & $\begin{array}{l}\text { Regressi } \\
\text { on } \\
\text { coefficie } \\
\text { nt }\end{array}$ & P-value & $\begin{array}{l}\text { Regressi } \\
\text { on } \\
\text { coefficie } \\
\text { nt }\end{array}$ & P-value \\
\hline \multirow{3}{*}{ Age } & $18-25$ & 38.31 & - & - & - & - \\
\hline & $26-35$ & 27.32 & -10.98 & $<0.0001$ & -8.32 & 0.04 \\
\hline & $36-45$ & 21 & -17.3 & 0.001 & -13.79 & 0.05 \\
\hline \multirow{2}{*}{ Gender } & Male & 39.38 & - & - & - & - \\
\hline & Female & 35 & -3.70 & 0.03 & -3.32 & 0.05 \\
\hline \multirow{4}{*}{$\begin{array}{l}\text { Academi } \\
\text { c level }\end{array}$} & $\begin{array}{l}\text { Bachelor's } \\
\text { degree }\end{array}$ & 37.32 & - & - & - & - \\
\hline & $\begin{array}{l}\text { Master's } \\
\text { degree }\end{array}$ & 29.63 & -7.69 & 0.01 & 1.14 & 0.77 \\
\hline & Ph.D. & 26.76 & -10.56 & 0.002 & 0.86 & 0.87 \\
\hline & Ph.D. & 43.24 & 5.91 & 0.03 & 6.29 & 0.02 \\
\hline \multirow{3}{*}{$\begin{array}{l}\text { Marital } \\
\text { status }\end{array}$} & Single & 38.41 & - & - & - & - \\
\hline & Married & 26.38 & -12.02 & $0.0001>$ & -8.37 & 0.001 \\
\hline & $\begin{array}{l}\text { Divorced/wid } \\
\text { ow }\end{array}$ & 37.5 & -0.57 & 0.93 & 2.69 & 0.71 \\
\hline \multirow{4}{*}{$\begin{array}{l}\text { Accomm } \\
\text { odation }\end{array}$} & Local & 35.40 & - & - & - & - \\
\hline & Dormitory & 38.23 & 2.82 & 0.09 & - & - \\
\hline & Private house & 34 & -1.40 & 0.72 & - & - \\
\hline & Other & 30.25 & -5.1 & 0.27 & - & - \\
\hline
\end{tabular}

\section{Discussion}


The present study showed that $3.7 \%$ of the students were addicted to the Internet and social networks and $27.4 \%$ of them were at risk of internet addiction. In comparison, the internet addiction rate was $2 \%$ lower and the risk of internet addiction was $17 \%$ less in a study conducted by Asiri et al. (2013) on students of Guilan University of Medical Sciences in 2012 [7].Bahrainian reported the prevalence of Internet addiction among students of Birjand Azad University to be 40.7\% [18].Another study by Ghamari et al. (2011) on students at Arak University found the prevalence of Internet addiction was 2.8\% [19].It seems that the main reason for these conflicting results for the prevalence of Internet addiction in different studies is the difference in the instruments used for measuring Internet addiction. For instance, Ghamari et al. (2011) used Young's Internet Addiction Diagnostic Questionnaire (IADQ), which is very similar to the questionnaire used in the present study and the internet addiction prevalence was almost the same in both studies.

The results of the present study indicated that of the social media commonly used in the country, $7.95 \%$ of students used Telegram, $75.9 \%$ used Instagram, and 55.9\% used WhatsApp messenger. Delshadi et al. (2016) surveyed social networking usage of students of Ilam universities and found $64.8 \%$ of students used WhatsApp messenger, $44.2 \%$ of students used Viber, and $20.8 \%$ of them used Facebook [20].At the time of their study, online education and online media were not commonly used.

The present study found a significant negative correlation between Internet addiction and happiness, indicating that as the value of one of these variables increased, the other variable decreased. This finding was consistent with the results reported by Rastgar et al. (2014) and Akin (2012). These two studies found that Internet addicts had a lower level of 
happiness than normal people, and as the severity of addiction increased, their level of happiness decreased [11, 21, 22].Besides, since Internet addiction is associated with anxiety, low self-esteem, and loneliness, and happiness is associated with self-confidence and positive emotions, this negative association seems reasonable [23-26].

The findings of this study also showed a significant positive correlation between Internet addiction and depression, indicating that internet addiction increases depression among the students and vice versa. Likewise, Bahrainian et al. (2014), Noori and Sadeghyan (2017), and Nie et al. (2017) found a significant correlation between Internet addiction and depression. There is a two-way relationship between Internet addiction and depression in that a person's depression leads him/her to resort to the Internet and social media. On the other hand, excessive use of social networks leads to depression and lack of communication with others, which in the long run causes more depression resulting in a vicious cycle, worsening the situation of a person who is addicted to the Internet and social media $[18,27,28]$. Furthermore, previous studies have shown that depressed people have low self-esteem and do not dare to express their opinions in public, but they can use social media anonymously to express themselves, and this is one of the reasons for the excessive use of the Internet and social media [27].Another factor accounting for the correlation between Internet addiction and depression is the effect of being on social media, observing the situation of other users of these media, and comparing one's life with other people's life displayed in media such as Instagram and Facebook. They post some images and materials (albeit unrealistically) that display them happy and successful. Therefore, people 
who use these media regularly may compare their living conditions with those of others and thus suffer from depression and lack of self-confidence [2, 29].

The present study also showed no significant relationship between Internet addiction and academic achievement. In contrast, Ajam and Rezvany (2017) and Behbodi and Behzadirad (2014) showed that if the internet and social media, and networks are used properly they can have positive effects on student learning by increasing interaction with other students, ease of access to resources, sharing scientific experiences, and improving academic performance $[30,31]$.

The findings of this study suggested a negative relationship between age and Internet addiction, indicating that as a user's age increases he/she will be less dependent on the Internet and social media. Accordingly, the students in the age group of 18-25 years had a higher internet addiction score than the students in other age groups. Asiri et al. (2013) and Mohamady et al. (2014) found a negative relationship between age and Internet addiction. They also reported that people in the age group of 18 to 24 years had the highest mean score of Internet addiction [7, 32].However, Vahabi et al. (2015) found no significant relationship between age and Internet addiction [12].This can be attributed to the smaller number of students in higher age groups. However, the present study focused on students in different age groups. Perhaps one of the reasons for the high prevalence of Internet addiction among the student aged 18-25 years was their interest in seeking diversity and fun compared to other age groups.

According to the findings of the present study, the mean score of the Internet and social network addiction in females was significantly lower than males. Similarly, Vahabi et al. 
(2015) Ghamari et al. (2011) found that males had a higher mean score of social media addiction than females $[12,19]$. This result has been observed in other studies [3234].However, some studies reported a higher mean score for social media addiction for females $[35,36]$.A higher score of Internet addiction in males may be due to their greater interest in playing online games and following the news on social networks.

The results of the present study suggested that the single students were more exposed to Internet addiction than married students and there was a statistically significant difference between marital status and the mean score of Internet addiction. Dargahi (2007) and Mohamady et al. (2014) examined the factors affecting Internet addiction and found that Internet addiction is more prevalent in single people than married people [32, 37].However, Ghamari et al. (2011) reported a higher rate of Internet addiction in married students than single students [19].Accordingly, single students seem to have more leisure time than married students. On the other hand, the burden of marital and educational responsibilities on married students significantly reduces their chance of using the Internet excessively and therefore significantly become less dependent on the Internet compared to single students.

\section{Limitations}

One of the limitations of this study was that it used cross-sectional data and the relationships found in this study cannot be considered as causal relationships. Besides, the sample in the present study was limited to students of Kerman University of Medical Sciences and the findings may be generalized to other universities in the country. As another limitation of the study, the data were collected using self-report instruments from 
the students and the accuracy of the data depended on the accuracy of the students' responses, and the researchers assume that the accuracy of the responses was the same for all participants.

\section{Conclusion}

There is a two-way relationship between Internet addiction and depression in that a person's depression leads him/her to resort to the Internet and social media. On the other hand, excessive use of social networks leads to depression and lack of communication with others, which in the long run causes more depression resulting in a vicious cycle. Therefore, the negative effects of this technology on students' lives and the consequences of its improper use can be reduced by teaching and applying preventive strategies. Furthermore, a culture for effective use of online social media can be built by making the best use of the benefits of online education and enhancing students' use of social media and networks for educational purposes.

\section{Suggestions}

Given the growing influence of the Internet and social networks in the lives of students, especially in the current situation, further research is needed to investigate the different effects of using the Internet and social media and networks on the capabilities and performance of students in its various aspects. Consequently, useful information on the positive and negative effects of using the Internet and social networks should be provided to students. Besides, university officials and educational policymakers can use the frequent presence of students in social media and networks for educational purposes. They can also 
hold short-term training courses for students and faculty members to get them familiar with the educational and research functions of social media.

\section{Acknowledgments}

We would like to thank the nurses involved in this study as well as the cooperation of the Research Council and the students of Kerman University of Medical Sciences

\section{Abbreviations}

Kerman University of Medical Sciences (KMU), Oxford Happiness Inventory (OHI) the Patient Health Questionnaire (PHQ-9),

\section{Authors' contributions}

EN, AA, and HSh. wrote the main manuscript text. HSh analyzed and interpreted the questionnaire data. EN, AA and HSh co-wrote and approved the final manuscript.

\section{Funding}

All resources were provided by Brighton and Sussex Medical School. No external funding was granted. The funder had no input into data analysis and interpretation, manuscript writing, and dissemination of results.

\section{Availability of data and materials}

The datasets used and/or analyzed during the current study are available from the corresponding author on reasonable request. We do not have ethical permission to upload the dataset into a repository. Please note that all study data has been anonymized for confidentiality purposes.

\section{Ethics approval and consent to participate}


This study was approved by Ethics Committee Kerman University of Medical Sciences (KMU) committee on 2019 (IR.KMU.REC.1397.515.). Information was provided to all participants and written consent was obtained prior to the start of the online questionnaire. All methods were carried out in accordance with relevant guidelines and regulations in the Ethical Declarations.

\section{Consent for publication}

Not applicable.

\section{Competing interests}

The authors report no actual or potential conflicts of interests.

\section{References}

1. Bullen P, Harré N: The Internet: Its effects on safety and behaviour. J Implications for adolescents 2000.

2. Azizi SM, Soroush A, Khatony A: The relationship between social networking addiction and academic performance in Iranian students of medical sciences: a cross-sectional study. BMC psychology 2019, 7(1):28.

3. Arashloo $\mathrm{H}$ : The survey and comparision of internet on identity and mental health. $J$ Tehran: Azad University of Roodehen branch 2006.

4. vahidi far $\mathrm{H}$, nabavi zadeh $\mathrm{H}$, ardebily fard $\mathrm{M}$ : Assessment of internet addiction among college students in North Khorasan University of Medical Sciences in Bojnoord, Iran. Journal of North Khorasan University of Medical Sciences 2014, 5(5):1081-1088.

5. Block JJ: Issues for DSM-V: Internet addiction. Am Psychiatric Assoc; 2008.

6. Goldberg I: Internet addiction disorder-Diagnostic criteria. Internet Addiction Support Group (IASG). 1995.

7. Asiri S, Fallahi F, Ghanbari A, Kazemnejad-leili E: Internet addiction and its predictors in guilan medical sciences students, 2012. Nursing and midwifery studies 2013, 2(2):234.

8. Young K: Internet addiction test (IAT): Stoelting; 2016.

9. Young KS: Psychology of computer use: XL. Addictive use of the Internet: a case that breaks the stereotype. Psychological reports 1996, 79(3):899-902. 
10. Donnelly E, Kuss D: Depression among users of social networking sites (SNSs): The role of SNS addiction and increased usage. Journal of Addiction and Preventive Medicine 2016, 1(2):107.

11. Rastgar S, Abdollahi M, Shahgholian M: Internet addiction, social intimacy and happiness in college students. Developmental Pschology: Iranian Psychologists 2014, 11(42):159-168.

12. Vahabi A, Vahabi B, Rajabi N, Taifuri s, Ahmadian M: Evaluation of internet addiction and its related factors in the students of Kurdistan University of Medical Sciences, 2015. Journal of Medical Education Development 2015, 8(19):99-110.

13. Khajeahmadi $M$, Pooladi S, Bahreini $M$ : Design and Assessment of Psychometric Properties of the Addiction to Mobile Questionnaire Based on Social Networks. Journal of Nursing Education 2017, 4(4):43-51.

14. Young KS: Caught in the net: How to recognize the signs of internet addiction--and a winning strategy for recovery: John Wiley \& Sons; 1998.

15. Argyle $M$, Martin $M$, Crossland J: Happiness as a function of personality and social encounters. Recent advances in social psychology: An international perspective 1989:189203.

16. Alipoor a, Noorbala aa: A Preliminary Evaluation of the Validity and Reliability of the Oxford Happiness Questionnaire in Students in the Universities of Tehran. Iranian Journal of Psychiatry and Clinical Psychology 1999, 5(1):55-66.

17. Kroenke K, Spitzer RL, Williams JB: The PHQ-9: validity of a brief depression severity measure. Journal of general internal medicine 2001, 16(9):606-613.

18. Bahrainian SA, Alizadeh KH, Raeisoon MR, Gorji OH, Khazaee A: Relationship of Internet addiction with self-esteem and depression in university students. Journal of preventive medicine and hygiene 2014, 55(3):86-89.

19. Ghamari F, Mohammadbeigi A, Mohammadsalehi N, Hashiani AA: Internet addiction and modeling its risk factors in medical students, iran. Indian journal of psychological medicine 2011, 33(2):158-162.

20. Delshadi Z, Ghorbani M, Delshadi M, Safari O, Pashei T, Mansourian M: Survey of social networking usage and its relationship with the study status of students of llam universities 2015. Rahavard Salamat Journal 2016, 2(2):41-49.

21. Bandani Tarashoki E, Beiranvand R, Mehranfard S, Ahmadi Majin S, Pelarak F, Madmoli Y, Davoodi S, Najarian M: Relationship Between Internet Addiction and Feelings of Happiness at Dezful University of Medical Sciences. Iranian Journal of Nursing Research 2017, 12(1):23-29.

22. Akin A: The relationships between Internet addiction, subjective vitality, and subjective happiness. Cyberpsychology, behavior and social networking 2012, 15(8):404-410.

23. Diener EJAp: Subjective well-being: The science of happiness and a proposal for a national index. 2000, 55(1):34.

24. Ferraro G, Caci B, D'amico A, Blasi MDJC, Behavior: Internet addiction disorder: an Italian study. 2006, 10(2):170-175.

25. Kraut R, Patterson M, Lundmark V, Kiesler S, Mukophadhyay T, Scherlis WJAp: Internet paradox: A social technology that reduces social involvement and psychological wellbeing? 1998, 53(9):1017.

26. Diener E, Seligman MEJPs: Very happy people. 2002, 13(1):81-84. 
27. Nie J, Zhang W, Liu Y: Exploring depression, self-esteem and verbal fluency with different degrees of internet addiction among Chinese college students. Comprehensive psychiatry 2017, 72:114-120.

28. Noori R, Sadeghyan $\mathrm{N}$ : Internet addiction and its relationship with anxiety, stress, depression and insomnia in nursing and midwifery students of Bojnourd Islamic Azad University. Health-Based Research 2017, 3(1):51-57.

29. Kawyannejad R, Mirzaei M, Valinejadi A, Hemmatpour B, Karimpour HA, AminiSaman J, Ezzati E, Vaziri S, Safaeepour M, Mohammadi S: General health of students of medical sciences and its relation to sleep quality, cell phone overuse, social networks and internet addiction. BioPsychoSocial medicine 2019, 13:12.

30. ajam a, rezvany a: The Relationship Between the Use of Virtual Social Networks with Academic Achievement and Students' Confidence in Interpersonal Relations at Birjand University of Medical Sciences. Journal of Medical Education Development 2017, 9(24):33-43.

31. Behbodi M, Behzadirad F: Relationship Between Addiction to the Internet and Academic Achievement among Hormozgan University Students. Information Technology Management Studies 2014, 8(2):33-46.

32. Mohamady Z, Khatony A, Hydary M, Bahreini M: Internet Dependency in Students of Kermanshah University of Medical Sciences. Iranian Journal of Medical Education 2014, 13(12):1019-1030.

33. Mohammadbeigi A, Mohammadsalehi NJJoGUoMS: Prevalence of internet addiction and related risk factors in students. 2011, 20(78):41-48.

34. Tsai HF, Cheng SH, Yeh TL, Shih C-C, Chen KC, Yang YC, Yang YKJPr: The risk factors of Internet addiction-a survey of university freshmen. 2009, 167(3):294-299.

35. Al-Gamal E, Alzayyat A, Ahmad MMJPipc: Prevalence of I nternet Addiction and Its Association With Psychological Distress and Coping Strategies Among University Students in J ordan. 2016, 52(1):49-61.

36. Hosseini Beheshtian M: Comparison of internet addiction between girl and boy student of universities of Tehran. Womens Studies 2011, 2(2):23-42.

37. Dargahi $H, M . R$ : Internet addiction and its effective factors in residents of Tehran 2 nd district. Payesh 2007, 6(3):265-272. 